\title{
1. Fairness in a system of cooperative, joint production
}

Adam Smith (1994) tells us, in some of his most familiar passages, that highly productive societies in his time were characterized by extensive division of labor. This is no less true in our own time, and is once again a topic of economic research. ${ }^{1}$ Whether division of labor causes higher productivity, as Smith argues, or division of labor and increased productivity are joint results of other characteristics of modern societies, the association of division of labor with high productivity means that division of labor is a cooperative activity, one that is, or at least could be, a source of mutual benefits. This also extends beyond the production of goods and services for sale to the differentiation of roles in unpaid activities such as child-rearing. ${ }^{2}$ Briefly, cooperation with differentiation of roles produces a surplus over what we would have otherwise. But this immediately raises the problem of fairness: how might this surplus be fairly shared?

"Fair" and "cooperative" are both words with multiple meanings. The objective of this book is to explore the application of a particular sense of "fairness" to social situations that can be characterized as "cooperative or noncooperative games." Applications include intergenerational transfers, Pigovian taxes, interregional allocation, fair wages, and fairness issues arising from caste or racial divisions in society. The social situations combine some freedom of action on the part of individuals with elements both of mutual benefit and conflict of interest. This chapter will discuss the multiple meanings of the two key words "cooperative" and "fair," and the senses of these words that will be taken as given in the following chapters.

To say that an arrangement is "cooperative" is to say that it is entered into for mutual benefit by individuals who could choose other arrangements or courses of action. In common usage it is often vague, but in addition to just mutual benefit it seems to imply the choice of a common course of action or individual courses of action that are coordinated for mutual benefit. This is consistent with the use of the term in game theory, but the usage in game theory is, of course, more formal. In common usage "cooperative" also often seems to carry a positive value content. That is, in the absence of offsetting considerations, to cooperate is morally better than not to cooperate. This positive value load is not an aspect of the use of the word in game theory, however, as 
we will see. The word "cooperative" can also refer to organizations associated with the worldwide cooperative movement. This implies mutual benefit and voluntarism, but has further restrictions, including something of democratic or majoritarian decision-making. The word "cooperative" will not be used in that sense in this book.

As Schelling (1960) and Aumann (2004) have both pointed out, game theory can be better described as interactive decision theory. Thus the social situations envisioned by game theory are situations in which two or more agents each can freely decide among two or more courses of action, the outcome depends jointly on the decisions of all, and the interests or preferences of the individuals may be differently affected by the outcome. We often refer to the courses of action chosen as "strategies." A "strategy" may be just that, as the choice to attack or evade in a military conflict; but price decisions, voting decisions, and in principle any effective course of action, may be a "strategy." Game theory then addresses the determination of outcomes by decisions that are in some sense rational. "Rational" is also a word with many meanings. However, game theory has been strongly influenced by the use of the term in economics, where it means that decisions maximize something, such as a preference ranking or utility or profits. The object maximized is supposed to be an index of the individual self-interest of the decision-maker. Thus, cooperative action may require some contract or similar commitment, or some mechanism of enforcement. It may also require redistribution of the benefits generated by the cooperative action. Consider, for example, the cooperation between a poker cheat and their shill. The cheat signals the shill to bet when the cheat holds a good hand, and otherwise not. Thus, on average, the cheat wins more than the shill loses. In order to bring the shill into the agreement, the cheat must offer them a "side payment" to be made in secret after the game (and against its rules). Either party to the agreement might violate it: the shill by opportunistically playing to win with their own hand in some cases, and the cheat by refusing to make the side payment. Enforcement might take the form of threats of informal violence.

This example raises two issues with respect to fairness. The more obvious one is that the coalition of the cheat and the shill gains advantage by exploiting the other players in the game. Exploitation conflicts with fairness according to almost any concept of fairness. But let us consider another example, in which a group of people can either contribute or not contribute to the production of a public good. If all contribute equally, all are better off than they would be if none were to contribute; but if anyone refuses to contribute while all the others do contribute, the one who refuses is better off than the refuser would be if the refuser were to contribute. Thus, again, some enforcement will be required. Since all do better with the cooperative agreement than without it, cooperation produces a surplus (over what they would receive if there were 
no cooperation), yet there is no exploitation. But the surplus might then be distributed among the cooperators in infinitely many ways. Thus there seems to be no unique solution for the rational action of the group.

This issue arose in von Neumann and Morgenstern's (1944) founding book, which focused on what came to be called cooperative game theory. They found that the set of "solutions" to a game could be infinite, and a major objective of research in cooperative game theory for decades was to find reasonable ways to narrow this down by ruling out some of these infinitely many solutions. The decision among these infinitely many distributions is a collective decision, and the standard of rationality for collective decisions is at best mysterious. A number of the formulae of cooperative game theory are derived (at least partly) from standards of rationality for collective decisions. The Shapley (1953) value and Nash (1950) bargaining can be interpreted in this way, for example. Others are based on conditions of stability against deviations that might be rational for individuals or groups. The core and the nucleolus can be interpreted in this way, for example.

The continuum of possible solutions that arise in many cooperative games had a more or less contemporary parallel in welfare economics. The "new welfare economics" had set out to evaluate public policies relying only on the Pareto criterion of efficiency. However, it was found that in general, a continuum of Pareto-optimal market equilibria could occur. One proposal was that the Pareto-efficient equilibria could be ranked according to an equity criterion: that we might find a unique Pareto-efficient market equilibrium that would also be fair. Of course, a huge literature arose from that project, and it was huge in part because the word "fair" has multiple meanings. Some of those meanings would be clarified in the course of this research.

It is clear that fairness is not, in general, a criterion for solutions in cooperative game theory. The example of the poker cheat and their shill make that clear enough (and that example is an instance of a point made by von Neumann in his German-language writing on game theory in 1928, English translation 1959). In the cases of such solutions as the Shapley value, which can be interpreted as a model of group rationality, collective rationality and fairness in some sense may imply the same result. But the core, Nash bargaining, and the nucleolus cannot be thought of as fairness conceptions since the solutions in these cases depend on the agents' outside options; that is, transparently in the case of Nash bargaining, on bargaining power. It seems prima facie that bargaining power, like exploitation, is a concept inconsistent with fairness.

Given its focus on the determination of the distribution of the surplus, much of the literature on cooperative game theory makes no reference to the strategies chosen by a coalition in a cooperative game, but instead takes the game as being defined by the total value that can be generated by each possible coalition. When interactive decisions are represented in this way we 
speak of the game "in coalition function form," and much of cooperative game theory adopts this convention. This literature also relies on a set of simplifying assumptions that together are denoted as "transferable utility." That is: (1) that the motivating subjective benefits each agent derives from the outcome of the game are proportionate to money payments; and (2) that arbitrary lump sum redistributions of money may be made. The first of these two assumptions presupposes that the subjective benefits are numerically measurable, since otherwise no proportion between benefit and money could be calculated. Thus the assumption is utilitarian and cardinalist: if, for example, outcomes are evaluated only by preference rankings, no such proportion can exist. Further, the first assumption also conflicts with risk aversion, since we have long known that risk aversion corresponds with a diminishing marginal utility of money, to the extent that utilitarian measures of benefit are meaningful. But the second assumption is not innocent either. As some welfare economists have argued since the 1950s (Graff, 1957) lump sum redistributions may well be infeasible. In general, side payments may be costly, and some schedules of side payments may be infeasible. Thus, results for games in coalition function form may not be useful for some of the applications considered in this book. For these purposes, however, the modest literature on games in effectivity function form (e.g., Moulin and Peleg, 1982) may be more useful. The effectivity function is a function that tells us, for any coalition of players in the game, the set of outcomes which the coalition can impose on the group of players as a whole. The effectivity function must be derived from the specific strategies available to the agents, and some general results along these lines have been obtained. This can lead to a concept of stability that is a generalization of the core of a game in coalition function form. It does not require cardinal utility but only that each agent has a preference ranking over possible outcomes, risky as they may be. However, since for this approach outcomes are essentially public goods, there is no evident basis to judge the fairness of the result. In any case, some further work on characterizing cooperative outcomes of games will be needed for the purpose of this book. That will be an objective of the next two chapters.

Another reason for caution arises from the economist's concept of "rationality." Recent work in cognitive science and behavioral economics has made it clear that real human beings often are not rational as economic theory and game theory have commonly supposed. A formulation of stable decisions and outcomes in games that allows for some relaxation of that strict concept of rationality, and comparison of rational with less rational or nonrational decision processes, will be needed. That will also be discussed in the next chapter. For the balance of this book, a "cooperative" solution will be a set of strategies and outcomes that is stable in one or another of the senses that have been mentioned or in some sense that is explicitly derived from them. 
Efficiency has long been a topic of economic research. Fairness has been less studied but nevertheless there is an important literature in economics that does address fairness. Efficiency and fairness are concepts of evaluation: in order for them to be meaningful, there must be some predictable and stable objects to be evaluated. In economics, the objects evaluated are most commonly market equilibria. Decisions are usually supposed to be coordinated by market relations, as if in a great auction. Stability is a consequence of a particular schedule of prices that makes it impossible for anyone to benefit by deviating from the coordinated action. The questions of efficiency and fairness that arise pertain to "equilibria" that are stable in this limited sense. Game theory is in principle more general. Joseph Greenberg (1990) titled his restatement of game theory as The Theory of Social Situations. In what follows, very loosely following Greenberg, I will use the term "situation" to refer to a coordinated action together with its outcome.

To speak of efficiency or of fairness is to presuppose that the outcomes of the decisions made have some predictable relation to the interest, well-being, or welfare of the people who experience the outcomes. The simplest way to capture this is to suppose that the outcomes are money payments and, from the viewpoint of each individual, more money is better. Simple as this approach is, it addresses some important questions, as some applications of the "Prisoner's Dilemma" in game theory illustrate. A somewhat less problematic approach is to suppose that the influence of the outcomes on individual well-being can be measured by a number that can be the subject of ordinary arithmetic operations and that we might call "utility." This is flexible enough to capture anything that the "more money is better" approach can, to allow for attitudes toward risk, and to allow for a wide range of non-monetary benefits and for the different relative urgency of the wants satisfied by different outcomes.

This utility interpretation has a long history in economics, but it is at best a contentious history. While many economists have been persuaded that numerical utility is unscientific because there is no observable measure of the number, the founders of game theory began by proposing such a measure. In this they had little influence on the subsequent development of economic theory. For the economists who rejected numerical utility, the alternative, which is thought of as avoiding the problems of numerical utility, is that individuals have well-defined preference orderings over the outcomes of their joint action. A higher level in the preference ranking is identified with higher well-being or with greater realization of the individual's interests. Once again, this approach can explain any individual decisions that are predicted by the numerical utility or "more money is better" approaches, and this flexibility probably accounts for its prevalence among economists.

There is another reason why numerical utilities may not be appropriate for the present study. It is not what "ordinalist" economists might suppose. 
Numerical utilities do have behavioral consequences, Hicks (1954) to the contrary notwithstanding, and can in principle be measured, as von Neumann and Morgenstern (1944) demonstrated, following Lange (1934) and Zeuthen (1937). The more interesting question is to what extent alternative measures of utility may agree or disagree. But, for present purposes a point uniquely raised by Kennedy (1954) could be problematic: Kennedy writes, "Thus we shall hold that utility is a quantity, i.e., has magnitude; that it is indivisible; and that two utilities when added together do not yield another utility." In McCain $(2019 \text {, p. 105) })^{3}$ I referred to this as "the indivisibility of experience": utilities (if they exist) are subjective experience and not, per se, subject to arithmetic operations. I argued that this need not be a problem for welfare economics, since Pigou's (1920) "measuring rod of money" provides us with monetary counterparts of utility that can be added and in terms of which expected values can be computed; but for non-transferable utility games, a "measuring rod of money" may not be available.

The numerical utility approach gave rise to a natural interpretation of efficiency: one alternative is more efficient than another if the first gives rise to greater aggregate utility. The numerical utility approach did not really address fairness, but did guide economic redistribution, as it was argued that a redistribution toward equality of purchasing power would increase aggregate utility. This was not really an appeal to fairness: rather, it subsumes moral issues with regard to the distribution of purchasing power to efficiency. (This was a major reason for the anti-utilitarian economists to reject it.) But fairness or other criteria for redistribution seemed at first even more mysterious in the preference approach. Efficiency was expressed by the Pareto principle: if at least one person prefers situation $\mathrm{A}$ to situation $\mathrm{B}$, and nobody prefers situation B to situation A, then A is more efficient than B. Applied to the outcomes of market processes, this proves to be a powerful idea: under certain very optimistic assumptions, market equilibria would not fail to be efficient. It is true that if we make some less optimistic assumptions, the market equilibria might fail in terms of efficiency, but they fail in predictable ways in predictable cases, so efficiency in this sense remains a powerful policy tool.

The difficulty, however, is that prices always depend on the distribution of purchasing power. There could be infinitely many efficient actions, and it is not clear that one is better than another, or even that an efficient outcome is better, for the group, than some possibly infinite set of inefficient ones. To choose among outcomes even of market processes on the most optimistic assumptions, some value judgment additional to efficiency, or other than efficiency, would be needed. Nevertheless, the choice among public policies could not be avoided - not to choose, is to choose - and as Little (2002) argued, economic language such as "efficiency" is inherently valuative. The economic values are important ones for public policy decisions, but could not be conclusive 
without some judgments on the distributions of purchasing power among the individuals. But Little never gave specific form to the distributional judgment.

While the "more money is better" approach continued to play a part in game theory, both the numerical utility and preference approaches have been adopted widely. In "noncooperative" game theory - a tradition stemming from John Nash (1951) which sees coordination of action within "coalitions" of two or more agents as being very difficult and limited - numerical utility, as discussed by von Neumann and Morgenstern (1944) in their founding book, seems predominant. Preference approaches play some role. In cooperative game theory - a tradition that sees the formation of coalitions as easy - the "more money is better" approach has been predominant, but the preference approach plays a key part in some literatures including "effectivity theory" and Greenberg's restatement. However, all these literatures focus mainly on stability, in several senses, and neither efficiency nor fairness are important except as they influence stability. (Shapley's value theory and related concepts may be partial exceptions; see, e.g., McCain, 2013, Ch. 1.)

In economics, the preference approach was supposed to be "scientific" in that preferences could be observed. Provided that people are rational, their decisions would "reveal" their preferences, in that a rational person, faced with a set of alternatives, would choose the ones they most prefer. (It remains an assumption, not a fact, that the most preferred alternative is the one most in the individual's interest.) But the emergence of behavioral economics has made it much more difficult to regard individual decisions as simply rational (as other disciplines than economics might have argued long before). An extensive literature of experimental studies indicates that individual decisions commonly deviate from the decisions that are rational in the sense of preference or numerical utility theory.

This interpretation of the evidence in behavioral economics separates efficiency and stability conditions in a new way. Recall that under certain very optimistic assumptions, market equilibria would not fail to be efficient. This is because the market equilibrium price vector makes it irrational for any agent to deviate from the market equilibrium. If, however, individual decisions deviate from rationality (in this sense) then the market equilibrium might not be stable; and similar issues arise with respect to stability analyses in game theory, such as Nash equilibrium and the core. Accordingly, for the purposes of this chapter, we will need a representation of individual decisions that represents both the rational decisions (for efficiency and fairness) and any bias of actual decisions away from rationality (for stability analyses).

Chapter 2 will reconsider and extend some stability conditions from game theory using decision functions rather than preferences or numerical utility. For stability, it may be that the decisions are not "rational." It is the predictable decision that determines stability. These concepts will be extended in Chapter 
3. In Chapters 4 and 5, criteria of efficiency and fairness will be revisited in a similar framework.

Fairness is no less problematic than cooperation. Nevertheless it seems clear in the example of the poker cheat and their shill that their action is not "fair" because it is exploitative. In a broader sense, we may say that it is not "fair" because it considers only the interests of the cheat and the shill, but does not consider also the interests of the other players in the game. This suggests a preliminary condition for a criterion of "fairness": that it gives appropriate consideration to the interests of everyone affected by the decision. (The word "appropriate" will want further clarification.)

More generally, to be fair is, at a minimum, to be unbiased. Thus a criterion of fairness would take account of the interests of all who are affected by the decision in a way that reflects no bias among them. A utilitarian concept might do this. Utilitarian evaluation is unbiased in the sense that it counts each person equally: a unit of utility to one counts the same as a unit of utility to another. But the object of utilitarian thinking is usually to maximize utility. It seems unavoidably possible that an unfair decision might lead to the most total utility. The maximum of total utility requires that marginal utilities be equal; but this will correspond to equal total utilities only in a special case. If equal total utilities is not a fair distribution of utilities, then what would be? (This is addressed in passing in the appendix to Chapter 5.)

Since the appearance of Rawls's (1971) A Theory of Justice, discussions of fairness have taken on a new dimension. Rawls's most widely recognized ideas are the initial position, subject to a veil of ignorance, and the difference principle. Thus, with Rawls, we envision something that might be called a social contract arrived at from an "initial position." The social contract will determine some differentiation of roles and rewards, but at the initial position the agents who will be governed by the social contract do not know what their roles and rewards will be when the society is realized. Further, their ignorance is so radical, comprising what economists have sometimes called "Knightian uncertainty," that they cannot apply probabilistic methods. Nevertheless they are rational egoists and thus try to secure their best advantage to the extent that they can, despite this radical uncertainty. Accordingly they apply a max-min decision procedure, systematically choosing the alternative in each case that favors the least favored person in the realized society. This is the difference principle: inequality is tolerated just to the extent that it favors the interests of the least favored in the realized society. Because the agents at the initial position do not know what their interests will be in the realized society, their deliberation cannot be influenced by those interests, and so their decisions at this initial position can only be unbiased, thus fair.

Several qualifications should be kept in mind. First, there is no suggestion that this initial position is a real historical event, such as a constitutional con- 
vention. Rather, it is a manner of thinking, a discipline of thought; in Rawls's phrase (e.g., Rawls, 1993, p. 104), "a device of representation" that would "model citizens" rational autonomy" (ibid., p. 72). Such a device of representation enables us to treat fairness as a condition that is in some sense objective, rather than a matter of prejudice or convenience. Second, important as the difference principle is, Rawls gives priority to maximal equal liberty. Third, the difference principle need not be egalitarian in any conventional sense. ${ }^{4}$ It could be, as a matter of fact, that a society of extreme inequality would nevertheless produce such wealth that even the worst-off in that society could be better off in that society than in a more equal one. This illustrates the previous point: in the light of Rawls's reasoning, what is fair becomes a matter of fact rather than personal judgment of value.

However, Rawls's interpretation of the initial position is not the only possible one, nor the earliest instance of such reasoning in the twentieth century. In the 1950s, John Harsanyi $(1953,1955)$, then a laborer and night-school candidate for a masters degree in Australia, published two papers based on a veil of ignorance argument that made a case for the maximization of average utility as the criterion for unbiased decisions. Harsanyi claimed explicitly that this made judgments of welfare an objective, rather than a subjective matter. That Harsanyi drew a different conclusion than Rawls poses a problem for a theory of fairness based on the veil of ignorance. To resolve the problem briefly: Harsanyi addressed a different question, to determine a "social welfare function," that is, a function that would express aggregate welfare as a function of the allocation and distribution of resources and product. The earliest proposal for such a function was that it should be a sum of utilities of individuals; Harsanyi tells us that this is the only such function that is rational in a certain sense. And this sense of rationality is another key difference from Rawls. Harsanyi appeals to Marshak and Radner's (1954) theorem that any rational choice based on a transitive and consistent preference system over uncertain prospects can be expressed as maximization of the expected value of a utility function with determinate subjective probabilities.

Can the difference between Rawls and Harsanyi be resolved? As noted, they were addressing different questions. Harsanyi wanted to specify a social welfare function, Rawls a system of political ethics. Second, there is something of a gap in Harsanyi's logic. Rawls tells us that the agents behind the veil of ignorance are ignorant even of their concept of the good. We may take that to mean that risk aversion and preferences over uncertain prospects are characteristics of agents in the actual world, not available to the agents behind the veil of ignorance. Harsanyi concedes that individuals' expected value functions over the utilities of the various agents might be unequally weighted, depending on their idiosyncratic preferences over the welfare of others, such as their preference that their children would do well, but that being unaware 
of those preferences behind the veil of ignorance, only equal probabilities are reasonable; and, further, this assignment of probabilities is fair. But it seems that one could equally argue that, being unaware of the preferences they will have as agents in the actual world, agents behind the veil of ignorance have no consistent preference over the uncertain roles and rewards they will face in the realized world, and so the Marshak conception of rationality cannot apply. Instead they face radical uncertainty. Finally, Rawls's max-min criterion is itself expressive of fairness in a certain sense, the cake-cutting model (see Dubins and Spanier, 1961; Kuhn, 1967; but note also Rawls, 1993, pp. 71-72). We will return to these issues in a later chapter. The convention of the veil of ignorance will be used, but since the questions addressed by this book will differ somewhat from those considered by either Rawls or Harsanyi, the analysis will differ from both.

A common idea would be that it is fair for each person to get what they are entitled to or what they deserve. But this poses a further question: how do we determine what a person is entitled to or deserves? And how is it possible to answer this question with unbiased reasoning? Here, for fairness, we have the "device of representation" of the veil of ignorance. Can such a device of representation give us a model of unbiased reasoning about entitlement? If so, would the answers differ from those we obtain from Rawls's discussion of fairness? A more promising approach, supposing we can construct a theory of fairness, is to say that a person is entitled to or deserves what they may fairly receive. But even this could be problematic, since it treats fairness as an absolute condition, and absolute fairness, even if it can be defined, may not be attainable. All in all, then, "entitlement" and "desert" do not seem to be useful concepts for this chapter.

Nevertheless, Rawls's ordinary-language discussion of fairness leaves some issues to be clarified. It is not quite clear, for example, how we determine who is least favored. This issue arises in economic applications when fairness is interpreted in terms of ordinal preference theory. In the 1970s, a value analysis emerged in the context of ordinal preference theory, based on the preference approach together with a certain concept of fairness. If the common action of Irving and John gives to Irving outcome A and to John outcome B, and John prefers A to B, this joint outcome of their joint action is unfair. It is unfair in that, as preference is correlated with individual welfare or interest, Irving's welfare is greater or his interest better served than is John's, according to John's preference ranking. This was usually expressed by saying that John would "envy" Irving, and that fair equilibria would be "envy-free." However, these discussions were generally mathematically formal, and there was no intended reference to any emotional state such as envy or pity. ${ }^{5}$ Nevertheless, the language is confusing and will be avoided here. Further, this evaluation may lead to cycles. It could be that Irving would at the same time prefer what 
John possesses. If exchange were feasible, then exchange would eliminate the unfairness; but that will not always be the case. (For a simple ordinary-language example, see McCain, 2017, pp. 37-40.) This concept of fairness seems to have been influenced by Rawls, and in particular his difference principle, but also by mathematical discussions of cake-cutting models of fairness, which arose at least partly from game theory. The major focus of the literature, however, was on the possibility (or, more probably, the impossibility) that some situation might be both fair and efficient, in this preference-based sense. That literature will be adapted and modified in Chapter 4. Fairness in roughly this RawlsFoley sense is the criterion that will be used in what follows to distinguish fair solutions of cooperative games. This criterion will need to be generalized in the following chapters, to relax the assumption that decision-makers have well-defined preference fields. Nevertheless, the preference of one person for what another possesses can be made the basis of an evaluation of relative fairness; and indeed of two, one of which, with little if any precedent in the literature, will be distinguished as quasifairness.

The fairness literature from economics has had some impact on post-Rawls political philosophy, particularly Dworkin's resource-egalitarianism and, more broadly, what is called luck-egalitarianism. These ideas begin from a value judgment in favor of equality, which might be interpreted as requiring equalization of welfare. However, a difficulty arises for this view: people with expensive tastes (Dworkin, 1981, pp. 187, 202, 228-240). We suppose that John Doe simply requires more resources than others to attain the same welfare. Thus it appears that equality of welfare requires inequality of resources, with more given to those with expensive tastes. But this seems at odds with the value attributed to equality per se. One way in which some writers have attempted to avoid this problem is to argue that the public authority should equalize inequalities that are due to brute luck, but that expensive tastes are not a consequence of bad luck, and so establish no claim to be compensated. This is "luck equalitarianism."

In this literature, the concepts of welfare, tastes and luck are often vague, or "a rough intuitive notion of individual welfare" (Keller, 2002, pp. 530-531). That said, it is not clear that this argument attains its objective. Examples of persons with "expensive tastes" that do not merit equalizing compensation include a person who buys food at (expensive) Fortnum's rather than taking the effort to shop at a street market (Cohen, 1989, p. 911, quoted in Otsuka, 2010 , p. 233), a person who has cultivated a taste for fine wine (Keller, 2002, p. 529), or who chooses an inefficient way to consume freely provided manna (Otsuka, 2010, p. 227), or who chooses to burn down their own house (Keller, 2002, p. 529), or who "chops off his own legs ... his motivation is not important" (ibid., p. 540). In all of these cases, compensation is excluded because the person has chosen to have expensive tastes, and so may be held responsible 
for them. But expensive tastes might result from a lifelong handicap (Dworkin, 1981, pp. 240-244) or because of upbringing that is beyond the person's control. In these cases the deficit is due to brute luck and some compensation would be merited to equalize welfare.

But Otsuka (2010, p. 227) quotes from a conversation with Cohen a rebuttal that seems to apply to several of these examples: "we might have good reason to doubt that someone [who does these things] was responsible for his choice, given how senseless such a choice would be." If a person chooses irrationally, could the irrationality of the choice not be considered brute bad luck? This would seem to dispose of all but the first two of the examples here; and as to the first two, shopping at a luxury market and cultivated taste, it is hard to see how they are worse off, having chosen a more convenient or pleasurable course of action. (On cultivation of taste, see Stigler and Becker, 1977; McCain, 1981.) And if they are not worse off, why consider compensating them? This raises the question of just what is meant by welfare in this literature.

But before turning to this, perhaps the examples can be improved upon. For an example of rational choice of expensive tastes in economics, consider the Becker and Murphy (1988) model of rational addiction. The rational addict, having discounted their future misery in balancing it against the pleasure of getting high now, has chosen to become addicted. We might then hold them responsible for their misery and so not qualified for any special treatment. But is that right? It is the addict's high rate of time preference that makes addiction rational for them, and is it not their brute bad luck to be born with a high rate of time preference? And time preference is an aspect of their preferences, so it seems that it is a little shortsighted to say that they have chosen their preference for dope. How, rationally, could they have done otherwise? (This is not to suggest that rational addiction is common or even present in the empirical world.) Now consider an example that might have salience for a great deal of political discord today in countries such as the United Kingdom, France, and the United States. Consider a person born and raised in a remote, rural location where there is little economic opportunity. They prefer to live near their family home, and having chosen to live there, they are poor. An economist might say that their poverty is the price they pay to indulge their preference to live in this particular place, and so that they are no worse off for it. For a luck equalitarian, it might seem that this is an instance of preferences inculcated by upbringing, and so beyond the person's control, so that they might be eligible for subsidy (and people in these circumstances are very widely subsidized). But notice that a person with a similar preference to live near the family home, but who was born and raised in Palo Alto, California, would have no such disadvantage. It seems our rural homebody is indeed the victim of brute bad luck: not in their preferences, but in their place of birth. 
The relation of preference to welfare and to choice seems quite problematic in this literature. How could a person, by rationally choosing what they prefer, thereby put themself at a disadvantage relative to others? What is the "welfare" that is to be equalized in such a case? One possibility is that it is the economist's old friend, a cardinal utility function. In that context, it has long been known that idiosyncratic differences in the sensitivity to material circumstances could present a problem. In a response to Sir Roy Harrod (1938), Lord Robbins (1938, p. 636) expressed this with his characteristic elegance:

I well remember ... reading somewhere - I think in the works of Sir Henry Maine the story of how an Indian official had attempted to explain to a high-caste Brahmin the sanctions of the Benthamite system. "But that," said the Brahmin, "cannot possibly be right. I am ten times as capable of happiness as that untouchable over there." I had no sympathy with the Brahmin. But I could not escape the conviction that, if I chose to regard men as equally capable of satisfaction and he to regard them as differing according to a hierarchical schedule, the difference between us was not one which could be resolved by the same methods of demonstration as were available in other fields of social judgment.

Robbins is criticizing a program that would maximize total utility, so that it would give more income to the Brahmin (supposing he were right), while equalizing utility would give him less. But Robbins's point was that such differences in sensitivity would be unknowable, so that no cardinal utility function could be known. "Expensive tastes," whether the person can be held responsible for them or not, require individual utility functions specified to the units and constant of integration. Ringen (1995, p. 9) expresses this by saying that tastes can be decomposed into preferences (with respect to the composition of consumption) and expectation (with respect to the level of consumption). Expensive tastes correspond to differences in what Ringen calls expectation. Robbins's Brahmin's utility function evidently has an overall steeper slope than that of the untouchable; perhaps some examples of expensive tastes could correspond to a shallower slope.

Dworkin, however, solves the problem by calling on the economic literature on fairness. Dworkin denies that he is a luck equalitarian (Dworkin, 2002, p. 107) and describes his position as resource-equalitarianism. But what constitutes equality of resources? Dworkin (1981, p. 285) writes: "No division of resources is an equal division if, once the division is complete, any [person] would prefer someone else's bundle of resources to his own bundle." He cites work in the economics literature by Foley (1967) and Varian (1974), and following the terminology of that literature, calls this the "envy test." But the "envy test" is not enough, and clearing markets are also required. Substantially, Dworkin's resource-equality is Varian's "fair*" allocation. This disposes of the person who has cultivated a taste for fine wine: they would not prefer 
the consumption bundle of a person who, not having cultivated a taste for fine wine, drinks plonk. Thus the oenophile cannot be thought (by their own standards) less well off with the same expenditure. But this leaves a troubling issue for those whose "expensive taste" is a result of physical handicap. It seems unavoidable that a person with a lifelong handicap must be considered worse off than a person with the same nonhuman resources and without the handicap. But, Dworkin suggests (and this is a common theme in the literature on luck-egalitarian and resource-egalitarian standards), since the handicapped person would prefer not to have the expensive tastes they have - they would prefer not to be handicapped - they cannot be held responsible for the expensive tastes and so could be compensated. (For a treatment of preferences for preferences from a point of view of economics, see George, 2009.)

But there may be no finite compensation for some handicaps. With these considerations in mind, Dworkin then adopts something along the lines of Rawls's initial position, as Dworkin (1973) interprets it, but in which the agents at the initial position know something of their tastes, including their degree of risk aversion. They do not know whether in the realized world they will be handicapped, nor how. These agents then confront ideal markets for nonhuman resources and ideal insurance markets offering insurance against disability. Since they face these markets with equal purchasing power, they will trade to an allocation that is fair*, to use Varian's term. Those who choose not to purchase insurance may then be held responsible for their handicaps, if any. But these hypothetical transactions need not be realized. Rather, they are a source of information. The markets for resources tell us (on the one hand) what allocation of nonhuman resources will be equal in the sense that it is fair*, and (on the other hand) the markets for insurance tell us the average amount of insurance settlements for each sort of handicap, which Dworkin takes as the appropriate compensation for an equalitarian regime. Dworkin relies a good deal on ad hoc judgments as to the insurance policies that would be offered by a prudent insurer in this idealized insurance market. For example, insurance against low wages will be so expensive (due to moral hazard) that little or none of it will be sold; accordingly, in the real world (as Dworkin understands the case) there is no equalitarian case for equalization of labor incomes (Dworkin, 2002, p. 127). On the whole, Dworkin's problematic examples, such as expensive tastes, seem to have been more influential than the tools he uses to deal with them, especially the hypothetical insurance markets. Dworkin's use of the economic-ordinalist concept of fairness, however, has been extended to form the "first-person or continuity test" that distributive judgments "should track peoples' own assessments of their relative standing" (Hansen and Midtgaard, 2011, p. 341). This principle underlies judgments of fairness for the purposes of this book. 
Anderson's (1999, pp. 294 et seq.) important paper pointedly rejects "luck equalitarianism," and particularly the "no-envy criterion." Dworkin asserts that she has simply misunderstood this (e.g., Dworkin, 2002, p. 294). Now, Anderson's article - which, on the whole, is a valuable and important contribution - does give some examples of the hazard of importing ideas from economics to philosophy, as in her apparent confusion on the incentive effects of a social dividend (Anderson, 1999, p. 299). But, with respect to envy, it may be that this is not confusion but rather her method, which assumes that public policies in general are expressive of emotional states. The reference to "pity" as the motivation of those who advocate transfers as a means of supporting "envy-free" equilibria is found in Anderson, but not, so far as I can discover, in any of the economic work on fairness. Now, it is true and important that public policies may induce emotional responses; as, for example, acceptance of transfers in support of the poor may cause the recipients to be ashamed. This is problematic not only in that the experience of shame in such a case is regrettable, but also because it is one reason for incomplete take-up of the programs, reducing their effectiveness. But this is a different thing. Anderson calls for a society in which all persons are treated with respect, and sees pity and envy as in conflict with respect. Fair enough; but how is public policy to realize that standard? In any case, there is still a danger of causing confusion, since according to Anderson, if the invidious interpretations (here I deliberately use Veblen's, 1899, term) were eliminated, perhaps through education, the same distributions of resources would no longer be unfair. But according to the preference condition, they would still be unfair, even if at the emotional level the gainers and losers by transfers treated one another with perfect respect.

In the literature of luck or resource egalitarianism, the standard is a society of equals. This is an absolute standard. In common usage - and often in scholarly studies, such as the economic literature on fairness - fairness is usually treated as an absolute condition: the social situation either is fair or it is not. For the purposes of this book, it will be useful instead to be able to say that one situation is more fair than another, even if neither is perfectly fair. Thus, what is needed is a criterion of relative fairness. Efficiency also remains a concern, but efficiency is at base a relative concept. The question to be addressed, then, is this: are there rules for the evaluation of relative fairness and efficiency that would be chosen unanimously if those affected were to choose behind a Rawlsian or Harsanyian veil of ignorance? And if so, what are they? The objective then will be to apply those rules to choose among coordinated strategies for a cooperating group.

This will require more extensive and deeper discussion, both formal and informal, to fill in the details around this sketch. This will be the objective of the following chapters. 


\section{NOTES}

1. See, for example, Acemoglu and Restrepo (2019), Costinot (2009), Zeira (1998).

2. See Elizabeth Anderson (1999, pp. 321-322), for a particularly powerful statement of this view.

3. Some of the following paragraphs reflect discussions in that book, particularly at Chapter 8 , the appendix to Chapter 8 , and Chapter 10. For the sake of continuity, no further references to the book will be made in this chapter.

4. A brief comment on Tomasi's (2012) Free Market Fairness may be in order here. Extensive discussion would be digressive, as Tomasi's objective is what he calls political philosophy, while the purpose of this book is what he calls public policy. Tomasi makes a case, within the framework of Rawls's veil of ignorance, that freedom to own a business is per se a component of individual welfare, that is, a primary good, and moreover one that should be grouped along with the maximal equal freedoms before, for example, wealth and position in the Rawlsian lexicographic order. Nevertheless he argues that this freedom is beneficial to the least favored. Many of Tomasi's arguments rest on assumptions of fact, without empirical support, but he considers possibility sufficient for political philosophy, while empirical reliability might be required for public policy. In any case, this illustrates the key role of the primary goods in a Rawlsian analysis.

5. Anderson (e.g., Anderson, 1999, p. 294) pointedly rejects this idea. This will be addressed later, following a discussion of some of the papers she was criticizing.

6. Varian uses this term, with the asterisk, for his distinctive definition. of fairness.

\section{REFERENCES}

Acemoglu, Daron and Pascual Restrepo (2019), “Automation and New Tasks," Journal of Economic Perspectives v. 33, no. 2 (Spring) pp. 3-30.

Anderson, Elizabeth S. (1999), "What Is the Point of Equality?" Ethics v. 109, no. 2 (Jan.) pp. 287-337.

Aumann, R.J. (2004), “Address,” Second World Congress of the Game Theory Society, Marseilles.

Becker, Gary and K.M. Murphy (1988), “A Theory of Rational Addiction,” Journal of Political Economy v. 96, no. 4 (Aug.) pp. 675-700.

Cohen, Joshua (1989), "Democratic Equality," Ethics v. 99, no. 4 (July) pp. 727-751.

Costinot, Arnaud (2009), "On the Origins of Comparative Advantage," Journal of International Economics v. 77, pp. 255-264.

Dubins, L.E. and E.H. Spanier (1961), "How to Cut a Cake Fairly," American Mathematical Monthly v. 68 (Jan.) pp. 1-17.

Dworkin, Ronald (1973), "The Original Position," University of Chicago Law Review v. 40 , no. 3 .

Dworkin, Ronald (1981), "What is Equality? Part 2: Equality of Resources," Philosophy and Public Affairs v. 10, no. 4 (Autumn) pp. 283-345.

Dworkin, Ronald (2002), "Sovereign Virtue Revisited," Ethics v. 113, no. 1 pp. 106-143.

Foley, Duncan K. (1967), "Resource Allocation in the Public Sector," Yale Economic Essays v. 7 (Spring) pp. 73-76.

George, David (2009), Preference Pollution: How Markets Create the Desires We Dislike (Ann Arbour, MI: University of Michigan Press). 
Graff, J. de V. (1957), Theoretical Welfare Economics (Cambridge: Cambridge University Press).

Greenberg, Joseph (1990), The Theory of Social Situations: An Alternative Game-Theoretic Approach (Cambridge: Cambridge University Press).

Hansen, Rasmus Sommer and Soren Flinch Midtgaard (2011), "Sinking Cohen's Flagship, or Why People with Expensive Tastes Should not be Compensated," Journal of Applied Philosophy v. 28, no. 4 (Nov.) pp. 341-354.

Harrod, Roy (1938), "Scope and Method of Economics," Economic Journal v. 48, no. 191 (Sept.) pp. 383-412.

Harsanyi, John (1953), "Cardinal Utility in Welfare Economics and in the Theory of Risk-taking,” Journal of Political Economy v. 61, no. 5 (Oct.) pp. 434-435.

Harsanyi, John (1955), "Cardinal Welfare, Individualistic Ethics, and Interpersonal Comparisons of Utility," Journal of Political Economy v. 63 (Aug.) pp. 309-321.

Hicks, J.R. (1954), "Robbins on Robertson on Utility," Economica v. 21, no. 82 (May) pp. $154-157$.

Keller, Simon (2002), "Expensive Tastes and Distributive Justice," Social Theory and Practice v. 28, no. 4 (Oct.) pp. 529-552.

Kennedy, Charles (1954), "Concerning Utility," Economica v. 21, no. 81 (Feb.) pp. 7-20.

Kuhn, H.W. (1967), “On Games of Fair Division,” Essays in Mathematical Economics in Honor of Oskar Morgenstern edited by M. Shubik (Princeton, NJ: Princeton University Press) pp. 29-37.

Lange, O.A. (1934), "The Determinateness of the Utility Function," Review of Economic Studies v. 1, no. 3 (Jun.) pp. 218-225.

Little, I.M.D. (2002), A Critique of Welfare Economics, 2nd edn reissued (Oxford: Clarendon).

Marshak, Jacob (1954) "Probability in the Social Sciences," Mathematical Thinking in the Social Sciences edited by P. F. Lazarsfeld (Glencoe, Ill.: Free Press)

McCain, Roger A. (1981), "Cultivation of Taste, Catastrophe Theory, and the Demand for Works of Art," American Economic Review v. 71, no. 2 (May) pp. 332-334.

McCain, Roger A. (2013), Value Solutions in Cooperative Games (Singapore: World Scientific).

McCain, Roger A. (2017), Approaching Equality: What Can Be Done About Wealth Inequality (Cheltenham, UK and Northampton, MA, USA: Edward Elgar Publishing).

McCain, Roger A. (2019), Welfare Economics: An Interpretive History (Routledge Advances in Social Economics) (London, UK and New York, USA: Routledge).

Moulin, H. and B. Peleg (1982), "Cores of Effectivity Functions and Implementation Theory," Journal of Mathematical Economics v. 10, no. 1 (June) pp. 115-145.

Nash, John (1950), "The Bargaining Problem," Econometrica v. 18, pp. 155-162.

Nash, John (1951), "Non-Cooperative Games," Annals of Mathematics v. 2 (Sep.) pp. 286-295.

Otsuka, Michael (2010), “Justice as Fairness: Luck Egalitarian, Not Rawlsian,” Journal of Ethics v. 14, no. 34 (Sept./Dec.) pp. 217-230.

Pigou, A.C. (1920), Economics of Welfare (London: Macmillan).

Rawls, John (1971), A Theory of Justice (Cambridge, MA: Belknap Press).

Rawls, John (1993), Political Liberalism (New York: Columbia University Press).

Ringen, Stein (1995), "Well-Being, Measurement, and Preferences," Acta Sociologica v. 38 , no. 1 , pp. 3-15.

Robbins, Lionel (1938), An Essay on the Nature and Significance of Economic Science (London: Macmillan). 
Schelling, Thomas (1960), The Strategy of Conflict (Cambridge, MA: Harvard University Press).

Shapley, L.S. (1953), "A Value for n-Person Games," in Contributions to the Theory of Games, Volume II (Annals of Mathematics Studies Number 28) edited by H.W. Kuhn and A.W. Tucker (Princeton, NJ: Princeton University Press) pp. 305-317.

Smith, Adam (1994), The Wealth of Nations (New York: Modern Library).

Stigler, George and Gary Becker (1977), "De Gustibus non est Disputandum," American Economic Review v. 67, no. 2 (Mar.) pp. 67-90.

Tomasi, John (2012), Free Market Fairness (Princeton, NJ: Princeton University Press). Varian, H.R. (1974), "Equity, Envy and Efficiency," Journal of Economic Theory v. 9, pp. 63-91.

Veblen, Thorstein (1899), Theory of the Leisure Class (New York: Macmillan).

von Neumann, John and Oskar Morgenstern (1944), Theory of Games and Economic Behavior (Princeton, NJ: Princeton University Press).

von Neumann, John (1959), "On the Theory of Games of Strategy," transl. by Sonya Bargmann, in Contributions to the Theory of Games, Volume IV (Annals of Mathematics Studies Number 40) edited by A.W. Tucker and R.D. Luce (Princeton, NJ: Princeton University Press) pp. 13-42.

Zeira, Joseph (1998), "Workers, Machines, and Economic Growth," Quarterly Journal of Economics v. 113, no. 4 pp. 1091-1117.

Zeuthen, Frederick (1937), "On the Determinateness of the Utility Function," Review of Economic Studies v. 4, no. 3 (June) pp. 236-239. 